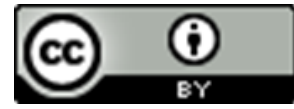

\title{
QUINTAL DE DONA LUIZA SOUZA COMO PARTE DA INSERÇÃO DA POPULAÇÃO NEGRA NA CIDADE
}

\author{
Luiza Maria de Souza ${ }^{1}$ \\ Márcia Aparecida de Souza ${ }^{2}$ \\ Henrique Cunha Júnior ${ }^{3}$
}

\begin{abstract}
Resumo: Este estudo apresenta o quintal da Dona Luiza Souza como patrimônio cultural. Pesquisou-se como se arquiteta esse quintal a partir dos conhecimentos sobre o uso da terra, do cultivo das plantas, da colheita e utilização dos produtos cultivados. Recolhemos os conhecimentos e também realizamos um levantamento das plantas medicinais, alimentícias e ornamentais encontradas no quintal da Dona Luísa Souza, 83 anos, de Natividade-RJ. A forma de trabalhar o quintal é parte de uma herança africana enquanto conhecimento. Esse quintal destaca-se pelo fato do cultivo de uma diversidade de plantas com finalidades medicinais, terapêuticas, alimentares e ornamentais de utilidades bem definidas e especificadas pela proprietária. Trata-se de um acervo de conhecimentos com fins bem detalhados e de uso da família, amigos e habitantes da região. É um estudo transdisciplinar que abrange as áreas de urbanismo, etnobotânica, farmacologia, patrimônio cultural, história de família e história urbana de população negra.
\end{abstract}

Palavras-chave: Quintais urbanos; geografia urbana; etnobotânica; história de população negra; forma urbana negra; patrimônio cultural.

\section{DONA LUIZA SOUZA'S BACKYARD AS PART OF THE INSERTION OF THE BLACK POPULATION IN THE CITY}

Abstract: This study presents Mrs Luiza Souza's backyard as cultural heritage. We researched how to build this backyard based on knowledge about land use, plant cultivation, harvest and use of land products. We gathered the knowledge and also carried out a survey of medicinal, food and ornamental plants found in the yard of Mrs Luísa Souza, 83 years old, from Natividade-RJ. The way of working the yard is part of

${ }^{1}$ Griot e Aposentada. E-mail: profmarciasouza2016@gmail.com ; Orcid: https://orcid.org/0000-0003$\underline{1430-7233}$

${ }^{2}$ Secretaria de Educação, Município de Natividades, RJ. E-mail: profmarciasouza2016@gmail.com ; ORCID: https://orcid.org/0000-0002-2761-3224

${ }^{3}$ Professor Doutor, Grupo de Pesquisa Etnicidade UFBA e UFCE. E-mail: cunhahenrique@yahoo.com ; ORCID: https://orcid.org/0000-0002-9664-5545 
an African heritage knowledge. This yard stands out for the fact that it cultivates a diversity of plants for medicinal, therapeutic, food and ornamental purposes with welldefined utilities and specified by the owner. It is a collection of knowledge with welldefined purposes for use by family, friends and inhabitants of the region. It is a transdisciplinary study in the areas of urbanism, ethnobotany, pharmacology, cultural heritage, family history and urban history of the black population.

Keywords: Urban backyards; urban geography; ethnobotany; history of black population; black urban form; cultural heritage.

\section{EL PATIO TRASERO DE DOÑA LUIZA SOUZA COMO PARTE DE LA INSERCIÓN DE LA POBLACIÓN NEGRA EN LA CIUDAD}

Resumen: Este estudio presenta el patio trasero de doña Luiza Souza como patrimonio cultural. Investigamos cómo construir este patio trasero basado en el conocimiento sobre el uso de la tierra, el cultivo de plantas, la cosecha y el uso de productos de la tierra. Recolectamos el conocimiento y también realizamos una encuesta de plantas medicinales, alimenticias y ornamentales encontradas en el patio de Doña Luisa Souza, 83 años, de Natividade-RJ. La forma de trabajar el patio es parte de una herencia africana como conocimiento. Este patio se destaca por el hecho de que cultiva una diversidad de plantas con fines medicinales, terapéuticos, alimenticios y ornamentales con servicios bien definidos y especificados por el propietario. Es una colección de conocimiento con propósitos bien definidos para uso de familiares, amigos y habitantes de la región. El estudio transdisciplinario en las áreas de urbanismo, etnobotánica, farmacología, patrimonio cultural, historia familiar e historia urbana de la población negra.

Palabras clave: patios urbanos; geografía urbana; etnobotánica; historia de la población negra; forma urbana negra; patrimonio cultural.

\section{L'ARRIÈRE-COUR DE DONA LUIZA SOUZA DANS LE CADRE DE L'INSERT DE LA POPULATION NOIRE DANS LA VILLE}

Résumé: Cette étude présente l'arrière-cour de Dona Luiza Souza comme patrimoine culturel. Nous avons recherché comment construire cette arrière-cour en nous basant sur les connaissances sur l'utilisation des terres, la culture des plantes, la récolte et l'utilisation des produits cultivés. Nous avons rassemblé les connaissances et mené une enquête sur les plantes médicinales, alimentaires et ornementales trouvées dans la cour de Dona Luísa Souza, 83 ans, de Natividade-RJ. La façon de travailler le chantier fait partie d'un patrimoine africain en tant que savoir. Cette cour se distingue par le fait qu'elle cultive une diversité de plantes à des fins médicinales, thérapeutiques, alimentaires et ornementales avec des utilités bien définies et spécifiées par le propriétaire. C'est une collection de connaissances à des fins très détaillées et à l'usage de la famille, des amis et des habitants de la région. Il s'agit d'une étude transdisciplinaire qui couvre les domaines de l'urbanisme, de l'ethnobotanique, de la pharmacologie, du patrimoine culturel, de l'histoire familiale et de l'histoire urbaine de la population noire. 
Mots clés: arrière-cours urbaines; géographie urbaine; ethnobotanique; histoire de la population noire; forme urbaine noire; héritage culturel

\section{1-INTRODUÇÃO: QUINTAL COMO PARTE DA CONCEPÇÃO PROJETADA DO URBANO}

$\mathrm{Na}$ história de cidades e do meio urbano uma das formas mais antigas de manuseio da terra são os jardins e quintais, espaços de usos múltiplos, mudando a paisagem e compondo um paisagismo, local onde normalmente se encontra ervas, árvores e arbustos. Os Jardins e quintais fazem parte de uma composição da paisagem que reúne o planejamento urbano, arquitetura e agronomia (FROTA JÚNIOR; WEHMANN, 2014). Também costuma apresentar uma composição florística diversificada, definida pela interação morador/planta. Brito e Coelho, (2000), definem quintal como espaço situado próximo às moradias, portanto de fácil acesso, no qual são cultivadas ou mantidas diversas espécies que proveem parte das necessidades de famílias ou de uma comunidade. Também segundo Santos e Cunha (2019), nessa área encontra-se uma diversidade capaz de suprir uma série de necessidades tais como alimento, lenha e ervas medicinais e de utilização em práticas religiosas.

Para Palheta (2015), quintal é o espaço ao redor das casas que proporciona sombra, oferece conforto ambiental e também é local de encontros familiares, conversa entre pares, além de ser próprio para acolher, receber e conversar com os amigos. $\mathrm{O}$ quintal é parte da sociabilidade entre indivíduos e comunidades.

Em algumas sociedades tradicionais os quintais se intercomunicam formando espaços de convivência e uso de diversas famílias, como é caso em comunidades de quilombos e bairros rurais negros (SANTOS, 2012).

Quintais podem ser considerados patrimônio cultural, pois tê-los e conservá-los envolve usos, costumes e saberes tradicionais que foram e continuam sendo transmitidos de geração para geração. Além disso, necessitam de conhecimentos sobre manejo e cuidados específicos do solo e das plantas por parte de uma família ou comunidade em relação à preservação das diferentes espécies de plantas que se encontram nesses espaços. 
O cuidar, cultivar, utilizar e socializar os resultados envolve uma diversidade de saberes específicos, tais como colher na época certa, conservar sementes, identificar época e lua adequada para plantio ou para arrancar determinada raiz, reconhecer uma erva entre outras plantas, saber quando e pra que utilizar a folha seca ou verde ou a utilidade de parte diferente da mesma planta (folha ou flor) para tratar diferentes afecções. Esse conjunto de discernimentos que envolve uma série de aprendizados, fazem parte da identidade de certas famílias ou comunidade, são saberes transmitidos de pais para filhos, práticas mantidas e guardadas pela memória, justificando a denominação patrimônio cultural.

Também ampara o termo, essas práticas envolverem sentimento de seguir a geração anterior, lembrando o que já existiu, existe e precisa ser conservado, para não de perder-se com o passar dos anos, pois se isso acontecer são mínimas as possibilidades de recuperação. Além de que as práticas e o conjunto de conhecimentos referentes ao preparo de chás, xaropes, sumos e banhos para o combate a diversas doenças são resistências culturais, pois veem sobrevivendo apesar da globalização e do predomínio do conhecimento científico acadêmico, atividades essas que podem ser entendidas como contracultura da importância desses saberes.

Práticas e conhecimentos locais que resistem a um período em que a industrialização domina, podem ser tidos como patrimônio, pois os vegetais cultivados nos quintais exteriorizam tradições e hábitos culturais de pessoas, famílias e populações que cultivam para o consumo. Portanto, compõem "sistemas sociais e culturais específicos, que atribuem distintos significados ao que se come e como, quando e com quem se come". (SANTILLI, 2015 p.587). Há uma proximidade entre o alimento e o que ele representa para o consumidor que o cultivou e o consome, uma relação de confiança, carregada de história e representatividade.

Os conhecimentos botânicos, transmitidos de geração em geração, mantidos como práticas culturais e valorados pela história, pela memória, pela salvaguarda de modos de plantar, colher, reconhecer plantas, empregá-las no consumo alimentar ou como medicamento, são tidos como um patrimônio cultural (RANIERI e ZANIRATO, 2018 p.185).

Quintal urbano, como é o caso do quintal de Dona Luísa, é um patrimônio cultural caracterizado por uma forma de viver no meio urbano que traz conhecimento e 
prática da vida rural, representa uma ligação com atividades características das sociedades agrícolas rurais. Pessoas que por diversas razões se transferiram para a zona urbana, nesse novo meio reproduzem práticas que antes realizavam no meio rural. Apesar dessa atividade ser realizada no novo meio e em dimensões territoriais bem menores, conservam as mesmas práticas culturais de produção.

O quintal em questão traduz a forma de vida da moradora e os conhecimentos obtidos ao longo de sua existência, herdados de gerações passadas. Dona Luísa teve uma infância no mundo rural marcada pelas brincadeiras de roda, de corda e de piques nos quintais. Quando jovem e na idade adulta assistiu a muitos casamentos, dançou bailes e participou de outras festas nos grandes quintais das casas da roça. Sentada em bancos de madeira no quintal amamentou seus filhos e realizou longas e agradáveis conversas com vizinhos, parentes e comadres. O quintal rural figura na memória como um lugar de convivência e sociabilidade, e produz a referência para o quintal urbano. Ainda com relação ao quintal rural, ali viu os filhos crescerem correndo pelo quintal, dali colheu diversos alimentos para sua família, além de recorrer a esse quintal para colher ervas para o preparo dos "milagrosos" chás, banhos e xaropes, entre muitas outras vivências naquela área, como por exemplo a criação de animais e a produção artesanal.

Esses sentimentos e emoções vividos provocaram um pertencimento, carinho e afeto por aquele local, pertença que foi passada para os filhos e agora tende a passar para os netos e bisnetos, dando-lhes através do espaço do atual quintal, oportunidades de vivenciarem experiências similares às que viveu há décadas. Essa repetição das experiências vividas nos terreiros entre uma diversidade de plantas é abarrotada de significados afetivos para Sra. Souza, que tem um entendimento e forma de perceber o mundo diferenciados e com forte presença de pertença em relação ao seu quintal, à saúde e criação dos filhos, netos e bisnetos, como ela mesma sugere ao afirmar que cultiva ervas medicinais em seu quintal por sabe qual deve usar em diferentes afecções que podem acometer algum de seus familiares e vizinhos. A memória e emoções vividas pela referida senhora em seu quintal constituem um Patrimônio Cultural Imaterial, conforme corrobora Santana e Simões (2015, p.92), ao apontar que "memória e patrimônio estão inter-relacionados já que ambos, quando ligados, fazem referência aos 
conhecimentos que conferem aos grupos sociais o sentido de pertença a uma determinada cultura e sociedade".

Também, quintal é um patrimônio afro brasileiro em razão de que nele se cultivam práticas de conhecimentos e origem africana que chegaram ao Brasil através do tráfico de escravizados do continente africano, que ocorreu por mais de três séculos e foi responsável pela travessia de milhares de africanos para o país, portadores de heranças africanas que também da chegaram junto desses, além de trazerem muitas das espécies vegetais que foram implantadas no país. Carregavam parte da cultura africana, o que contribuiu para o desenvolvimento do Brasil colonial e formação da cultura brasileira. As plantas que trouxeram da África foram muito utilizadas em rituais religiosos e na subsistência alimentar; muitas dessas ervas tinham propriedade medicinal e inclusive eram as únicas formas de tratamento e até mesmo de cura de diversas afecções. (BASTIDE, 2001).

Segundo Almeida (2011) especialmente nas regiões Norte, Sudeste e Nordeste já foi provado, através de levantamentos etnomédicos, o quanto é grande a utilização da medicina popular, influência da herança cultural africana. A manutenção dessa herança africana em vários âmbitos socioculturais brasileiros é uma das formas de resistência da população negra. Além disso é grande a diversidade de plantas de uso cotidiano alimentar, tais como o quiabo, o inhame, jaca, mamona e tamarino, espécies africanas que se adaptaram aqui e tornaram-se nativas no Brasil (ALMEIDA, 2011). A tamanha utilização e diversidade dessas espécies reitera o peso da cultura africana no país e torna indiscutível que o quintal, local de cultivo, é um patrimônio afro brasileiro pois nele era e são cultivadas práticas e conhecimentos de origem africana desde o período colonial à atualidade.

Tanto em áreas rurais quanto em áreas urbanas a riqueza da flora brasileira encontrada nos quintais nos diversos Estados do país é fonte de vida e saúde, visto sua utilização para diversos distúrbios, principalmente em populações carentes. Tratamento de afecções que vão desde tranquilizantes e diuréticos a tratamento de câncer por exemplo, são realizados por muitas pessoas com ervas do próprio quintal, comprovando a eficácia da medicina tradicional. Por todas essas evidências entende-se que há necessidade de conservar esse patrimônio para que os conhecimentos (plantio, cultivo, colheita e utilização) possam ser transmitidos às futuras gerações. É necessário manter 
as farmácias vivas que se encontra em diversos quintais pois a flora medicinal encontrada nesses espaços pode ser um caminho para a descoberta de novos medicamentos.

Este artigo tem como finalidade apresentar parte de uma pesquisa cientifica, transdisciplinar que se desenvolve há dois anos na cidade de Natividade, que os autores acreditam como sendo inovadora por abordar no campo do urbanismo e da constituição da cidade o quintal urbano de população afrodescendente como patrimônio cultural e como forma da inserção de populações negras no meio urbano. A pesquisa é de metodologia participante e nos moldes da pesquisa afrodescendente. Trata-se de uma pesquisa no campo da educação e formação da identidade da população negra, comungando com as áreas de geografia urbana e da história da população negra no período do pós-abolição.

\section{2-A GEOGRAFIA DA CIDADE E O QUINTAL DA SRA SOUZA}

O município de Natividade encontra-se na região noroeste do estado do Rio de Janeiro (Figura 1), a $362 \mathrm{~km}$ da capital do Estado, a uma altitude média de 182 metros acima do nível do mar, com extensão territorial de $387 \mathrm{~km}^{2}$. Dentro de uma região historicamente considerada agropecuária.

A cidade é banhada pelo rio Carangola, sub-afluente do rio Paraíba do Sul. É um rio que banha duas unidades da federação, percorre 06 municípios pertencentes ao Estado de Minas Gerais e 03 municípios que fazem parte Estado do Rio de Janeiro.

Natividade faz limite com os municípios de Itaperuna, Bom Jesus do Itabapoana, Varre-Sai e Porciúncula. A estrada estadual RJ-220, atravessa o primeiro distrito e o liga à Porciúncula pelo Norte e à Itaperuna pelo Sul; E a RJ-214, leva ao município de Varre-Sai a nordeste e a Raposo, que é distrito de Itaperuna, a sudoeste.

Possui três distritos, Bom Jesus do Querendo, Ourânia e a sede que é o município de Natividade, local da pesquisa. 
Figura 1- Localização de Natividade no Noroeste do Estado do Rio de Janeiro-RJ

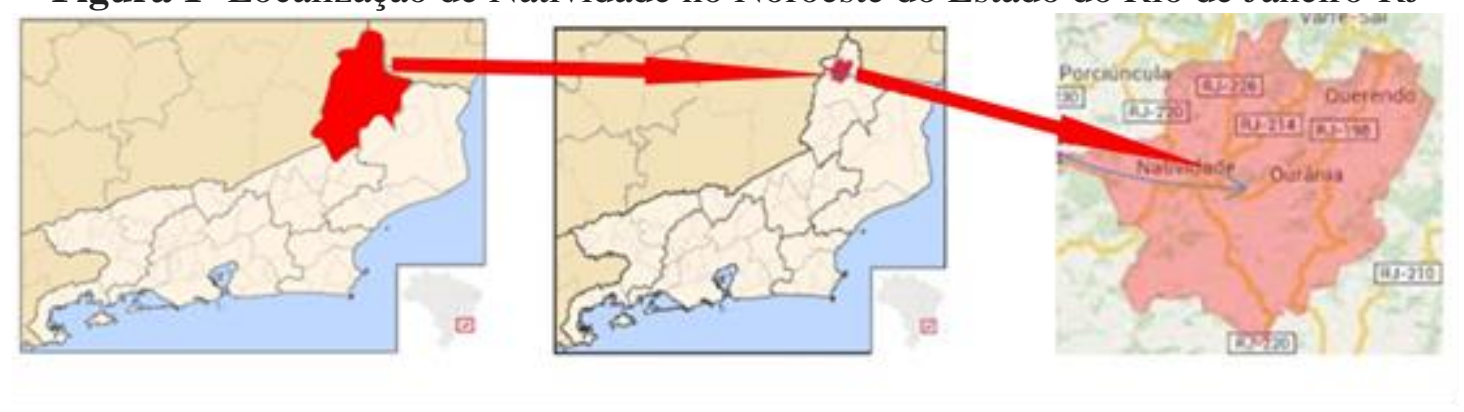

Fonte: https://upload.wikimedia.org/wikipedia/commons/0/0c/

RiodeJaneiroMunicipioNatividade.svg

Adaptação própria

A colonização de Natividade data do período entre 1821-1831, no século XIX. A cidade começou a se desenvolver nas proximidades do Rio Carangola. Durante décadas a atividade econômica predominante no município foi a agricultura, realizada através das mãos de negros escravizados que habitavam a região. $\mathrm{O}$ quantitativo de negros na localidade era bastante significativo, segundo Carvalho (2001), em 1872 contabilizava 1.832 pessoas escravizadas para um número de 3.803 pessoas livres, sendo que entre livres também figurava uma parcela da população negra. A agricultura baseava-se principalmente na produção de cana de açúcar, arroz, plantação de mandioca, milho, algodão e depois da metade do século XIX nas lavouras de café que aumentavam cada ano mais e tornou-se o motor da economia do município e região. Tanto que Itaperuna, Município ao qual Natividade pertencia na época, levou o Estado do Rio de Janeiro a ser classificado como primeiro colocado na produção do café, na safra de 1919-1920, representava na época $80 \%$ das rendas nacionais (CARVALHO, 2001).

Atualmente, a principal atividade econômica da região é a pecuária e o comércio. Também, o município apresenta certo potencial para o turismo constituído pelas antigas fazendas, pelos rios em região montanhosa e devido à aparição de uma Santa em um sítio pertencente ao referido município.

O quintal tratado neste artigo localiza-se na área urbana do município, no Bairro Balneário localizado no extremo da cidade. Esse bairro é um dos mais antigos da cidade, localiza-se à margem do rio Carangola. Os perfis de seus moradores, de um modo geral, são de classes média a baixa. Em Natividade temos vários bairros de características de população negra, inclusive muitos desses são considerados de grande 
vulnerabilidade social. O quintal da Dona Souza é localizado em uma quadra predominante de classe média o que indica a existência de um padrão de mobilidade social e econômica por parte de uma parcela pequena da população negra da região.

Figura 2: Bairro Balneário em Natividade-RJ

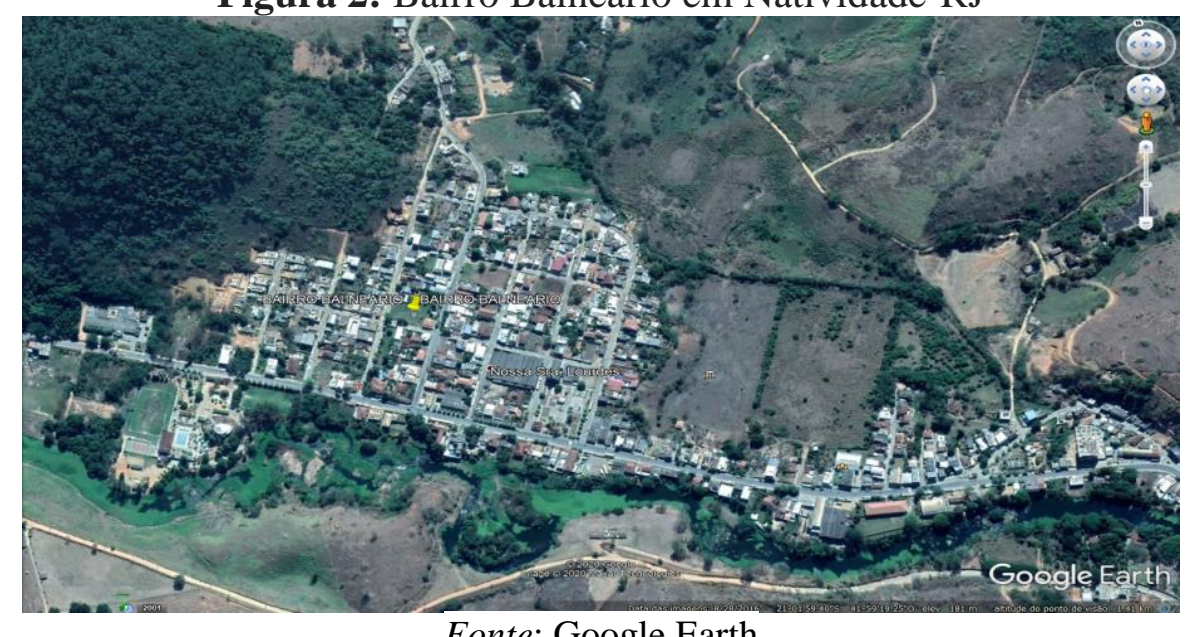

Fonte: Google Earth

Das nossas pesquisas sobre população negra e famílias negras deduzimos que no meio urbano das grandes cidades brasileiras os quintais de famílias negras eram comuns nas décadas de 1920 a 1970 (BARRETO, 2012), (MAVOUNGOU-YADE, 2015), (SILVA, 2018), (SILVA; CUNHA JUNIOR, 2014), (CUNHA JUNIOR, 2019), sendo que com a densificação populacional dos bairros eles tenderam a desaparecer. A seleção deste quintal para estudo deve-se a originalidade que o caracteriza tipológica e morfologicamente, no conjunto da história como um exemplo da transição entre o mundo rural e urbano, mas principalmente pelos conhecimentos revelados pela sua proprietária.

\section{3-METODOLOGIA}

A técnica de pesquisa utilizada para colher os dados foi visitas realizadas com a finalidade de explicar os objetivos e perspectivas da referida pesquisa, e também discutir melhor dia e horário para futuras visitas, subsídios auxiliares no ajustamento da metodologia a ser utilizada como ferramenta para a coleta de dados. Utilizou-se de um 
diário de campo, gravador de voz e câmara fotográfica para facilitar os registros de alguns relatos das abordagens formais e informais durante a pesquisa de campo.

A observação do quintal foi realizada de dezembro de 2019 a fevereiro de 2020. A entrevistada acompanhou todo o percurso pelo quintal e varanda ao redor de sua residência e também de um lote ao lado da residência da família, uma extensão do quintal, por ser anexo sem cercado separando-o da casa domiciliar.

Durante a entrevista questionou-se nome da planta, forma e tempo de cultivo, tipos de adubação, época de plantio, escolha das espécies que foram plantadas entre outras questões. Abordou-se também motivos que levam/levaram a entrevistada ao plantio, sobre dificuldades ou não do manejo com o quintal, sobre água para regar as plantas, visto o quintal localizar-se em área urbana. A entrevistada caminhava pelo quintal indicando o nome da planta, informava como conseguiu aquela espécie, melhor forma de cultivo e para que a planta era utilizada. Também a interlocutora apontou qual a parte da planta era usada, principalmente no caso da categoria medicinal; E se era consumida em forma chá, sumo, xarope ou utilizada para banhos, bochechos entre outras informações.

Além da técnica supracitada utilizou-se da metodologia afrodescendente, que é uma abordagem metodológica do campo da pesquisa empírica concebida para pesquisadores que possuem um envolvimento prévio com o tema da pesquisa. Para os que veem de dentro as preocupações e problemas da pesquisa em questão, que conhecem a temática através de vivências e não devido a leituras sobre o tema, aqueles que já realizam espontaneamente no seu dia a dia o que já conhece e que apenas ainda não está explicitado, como é o caso de Dona Luíza Souza, uma coautora desse estudo.

\section{4- HISTÓRIA, CONHECIMENTOS E CUIDADOS COM AS PLANTAS.}

Após fixarem residência na zona rural por 62 anos, os filhos do Sr. e Sra ${ }^{\mathrm{a}}$. Souza em comum acordo com os pais resolveram comprar um terreno na zona urbana e construírem uma casa para os pais, visto a idade mais avançada desses e possíveis necessidades de recorrer a auxílio médico. Ao escolherem o terreno para construção da nova casa tiveram o cuidado de também adquirirem uma posse ao lado para que os pais continuassem o cultivo de diversas plantas, como faziam na roça, há décadas. 
Assim que iniciaram a organização para compra do terreno, a anfitriã D. Luísa também iniciou uma criteriosa seleção e plantação de mudas de todas as plantas do quintal da casa da roça. Utilizando-se de vasos improvisados, reciclando latas de diversos tamanhos e potes de plástico, ela preparou a terra e plantou dezenas de mudas de plantas diversas.

Então do primeiro quintal vieram quase todas as plantas que há no quintal da atual residência. Mudas de mudas que anteriormente, há décadas foram sendo adquiridas através de trocas com os vizinhos, cultivadas de forma sustentável e cuidadas de maneira a não deixar acabar, foram preparadas para serem transportadas para o quintal da nova moradia, na zona urbana da cidade.

Mesmo antes de mudarem, quando Dona Luísa visitava a obra, também visitava o quintal e trazia quantas mudas pudesse. De forma que quando mudou em definitivo, o quintal já estava bastante sortido de plantas. Após a mudança grande porcentagem das plantas, principalmente as medicinais foram plantadas diretamente no chão, poucas em vasos.

Dona Luísa, como é conhecida na cidade, mora na nova casa aproximadamente há 2 décadas, e como na época da roça dificilmente procura auxilio médico. Afirma que ter seu quintal é algo indispensável em sua vida no que se refere à saúde, assim como na roça ainda hoje se alguém passa mal ela não dispensa o médico, mas afirma " sei qual a/as erva/s que vão fazer bem, então saio em meu quintal apanho as ervas coloco em uma vasilha, fervo um pouco de água coloco por cima, abafo e tomo ou dou meus filhos e netos pra beberem e em muitos casos não precisam mesmo procurar médico".

Sobre o cultivo e manutenção das plantas a depoente afirma que cultiva plantas comestíveis por gostar de ter certeza da procedência do alimento ou seja, ser seguro e saudável para consumo, pois os que cultiva ela sabe como foi cuidado, o que não acontece com vegetais cultivados em outros lugares. E os condimentos, afirma tê-los por não gostar de conservantes, procura evitá-los então prefere colher e utilizar.

A entrevistada afirmou que adora casa bonita e florida com flores naturais e a melhor forma de tê-las também é cultivá-las.

O quintal, com uma área que inicia no fundo da residência e se estende para o lado faz parte da paisagem construída da casa dessa família. Sr., $\mathrm{Sr}^{\mathrm{a}}$ Souza, filhos e netos plantam, cultivam, cuidam das plantas medicinais, frutíferas, alimentícias, 
ornamentais e leguminosas, sempre orientados pela dona Souza. Um aspecto que chama atenção é a responsabilidade dos integrantes da família, com os cuidados com o quintal, os filhos mesmo já casados e não mais residindo com os pais participam dos cuidados necessários com o quintal e a casa. Desse quintal são retirados alimentos de consumo diário, frutas de época e as ervas que compõem as receitas medicinais de Dona Luísa. A família também utiliza aquele espaço para reuniões familiares ou comemorações festivas. A presença e participação da matriarca e principal colaboradora tanto nas plantações quanto nos cuidados diários com a diversidade de plantas e espécies cultivadas é destaque, sem dúvida ela é figura fundamental (SOUZA; CUNHA JR., 2019).

Existe uma relação entre o cotidiano da vida da casa e o quintal, a própria rotina diária contribui para manter o solo sempre bem fertilizado, pois recebe diversas sobras de alimentos que se juntam às folhas e galhos que caem das árvores e às cinzas do fogão à lenha, o que certamente melhora a composição do solo. De forma que as plantas desse quintal crescem em um ambiente saudável e é boa a produção (Figura 4). Segundo Pedrosa (2016), a diversidade de espécies no mesmo espaço produtivo colaboram para o equilíbrio entre os insetos e contribui para o controle biológico.

Quando questionada sobre adubação afirmou que sempre usou esterco bovino para maioria das plantas, porém para condimentos e verduras utiliza-se também de esterco de aves. Aproveita folhas que caem das árvores ou que precisam ser retiradas das plantas para adubar as mesmas.

A cinza proveniente da queima principalmente de madeira é utilizada no combate a alguns fungos que atacam a cana de açúcar, bananeira e ramas de abóbora. As cascas de ovos, por vezes são utilizadas como adubo e ainda postas em uma estaca ao lado dos pés de couve na horta, para evitar que borboletas pousem e "botem ovos" nas folhas de couve.

Dentre as plantas frutíferas encontra-se maracujá, acerola, cajá-manga, uva, none, banana, mamão, laranja, goiabas, limão, abacaxi, lima, jabuticaba, pinha, carambola entre outras. Também há diversas raízes e caules, inhame, mandioca, araruta, batata doce e cana de açúcar. Completam-se com grande variedade de plantas medicinais, temperos além das ornamentais. 
Diariamente dona Luíza e a filha Maria Eugênia também preparam broas, bolos, geleias, polvilhos, farinhas e conservas com frutos e raízes do quintal para provimento da família.

Sobre o lazer e o prazer ao cuidar das plantas e do quintal a depoente afirma que seu maior lazer é cuidar de suas plantas, afirma que conversa com as plantinhas, e entende que essa interação para as plantas e para ela mesma. Comenta que fica feliz em andar pelo quintal e ver as plantas sobrevivendo, ano após ano. E todos os dias visita as plantas para ver o que estão precisando, cuida para não faltar água ou adubo, retira erva daninha ou uma lagarta que poderia prejudica-las. E a produção "agradece", a saber devido ao tamanho e qualidade dos produtos, as buchas vegetais que colhe para higiene corporal da família, amigos e vizinhos são enormes (Figura 3) e o mandiocal também produz belíssimas e "enxutas” raízes (Figura 5).

Figura 3: Bucha vegetal

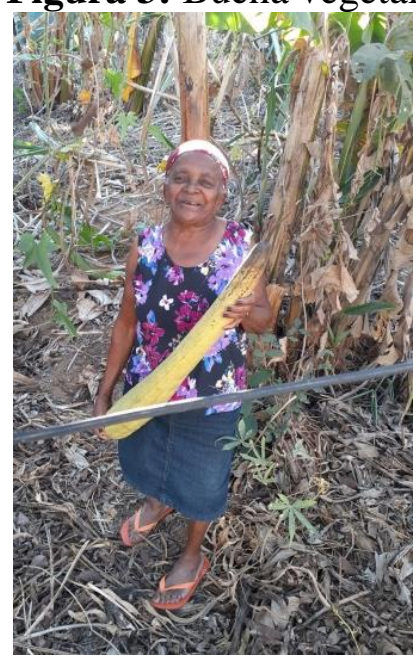

Fonte:Acervo Pessoal

Figura 4: Quiabal 


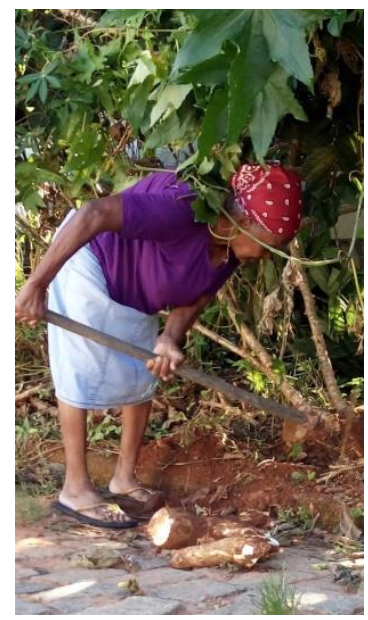

Fonte:Acervo Pessoal

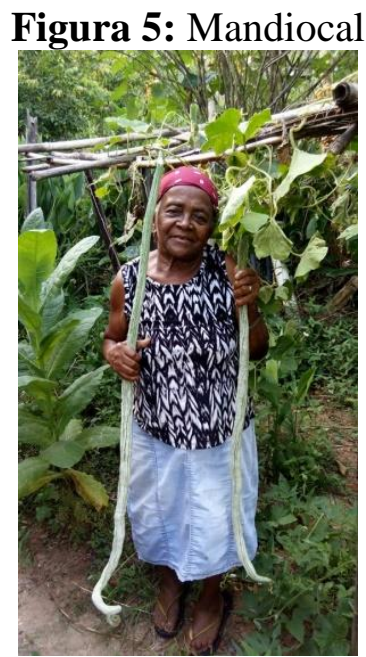

Fonte:Acervo Pessoal

Vale a pena registrar uma analogia feita por D. Luíza que afirma, quintal é como uma casa, é preciso cuidar, limpar e faxinar pra conservar. A casa precisa ser espanada, varrida, a pia precisa ser limpa e o lixo retirado. E no quintal é preciso tirar uma folha que seca, arrancar excessos da própria planta e replantar pra não tosseirar. $\mathrm{Na}$ casa o que é retirado de um lugar precisa ser novamente colocado no lugar, no quintal pela mesma forma, a planta retirada precisa ser replantada. Se tirar e não retornar, não mantem. "Eu retiro e replanto", conclui.

Todo esse manejo relatado por D. Luíza, que parte de princípios agroecológicos, demonstram também o patrimônio ecológico que a população negra possui e reitera uma das diversas formas de contribuição dessa camada da população que são os saberes, os 
conhecimentos etnobotânicos. Uma cosmovisão característica das populações negras e de baixa renda que tem indispensável função na preservação da biodiversidade e conservação dos ecossistemas em espaços urbanos e rurais (GOMES, 2009).

O conhecimento e experiência da referida senhora nos leva a entender que o domínio que ela possui sobre plantio, cuidados e preservação de seu quintal e consequentemente de suas plantas consiste em um patrimônio vivo.

\section{5- AS ESPÉCIMES E PARTES UTILIDADES E FORMA DE UTILIZAÇÃO/CONSUMO}

Através de entrevistas, indicações e descrições realizadas com Dona Luiza chegamos a listagem das espécies do quintal. Sendo que resolvemos classificá-las pela utilidade apontada pela depoente e as classificamos em quatro categorias, a saber: ornamentais, frutíferas, alimentícias e medicinais.

Tabela 1- Espécimes Medicinais

\begin{tabular}{|c|c|c|c|c|}
\hline & 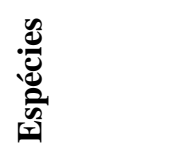 & 营 & ف & 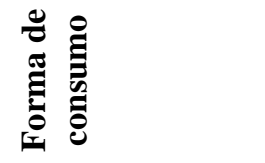 \\
\hline 01 & Arruda & Medicinal & Folhas & ------------- \\
\hline 02 & Assa-peixe & Medicinal & Folhas & Comp. xarope \\
\hline 03 & Açafrão & Medicinal/ Comestível & Raiz & $\begin{array}{l}\text { Pó na } \\
\text { comida/Tempero/ } \\
\text { Passar na Beira de } \\
\text { olhos e ouvidos }\end{array}$ \\
\hline 04 & Alecrim & Medicinal & Folhas & Chá \\
\hline 05 & Algodão & Medicinal & Folhas & Chá e banho \\
\hline 06 & Anador & Medicinal & Folhas & Comp. xarope \\
\hline 07 & Arnica & Medicinal & Folhas & $\begin{array}{l}\text { Chá/Banho/ } \\
\text { Comp.Xarope }\end{array}$ \\
\hline 08 & Boldo & Medicinal & Folhas & Chá \\
\hline 09 & Camomila & Medicinal & Folhas/Flores & Chá \\
\hline 10 & Confrey & Medicinal & Folhas & Chá \\
\hline 11 & $\begin{array}{l}\text { Conta de } \\
\text { lágrimas }\end{array}$ & Medicinal & Folhas & Chá/Banho \\
\hline 12 & Cana Criola & Medicinal & Folhas & Chá \\
\hline 13 & $\begin{array}{l}\text { Cana de } \\
\text { macaco }\end{array}$ & Medicinal & Folhas & Chá \\
\hline 14 & $\begin{array}{l}\text { Cordão de } \\
\text { Frade }\end{array}$ & Medicinal & Folhas & Chá \\
\hline
\end{tabular}




\begin{tabular}{|l|l|l|l|l|}
\hline $\mathbf{1 5}$ & $\begin{array}{l}\text { Erva de } \\
\text { passarinho }\end{array}$ & Medicinal & Folhas & Comp.Xarope /Sumo \\
\hline $\mathbf{1 6}$ & Erva cidreira & Medicinal & Folhas & Folhas \\
\hline $\mathbf{1 7}$ & Funcho & Medicinal & Fomp.xarope \\
\hline $\mathbf{1 8}$ & Fumo & Medicinal & Folhas verde & Banho \\
\hline $\mathbf{1 9}$ & Guaco & Medicinal & folhas & Comp.xarope \\
\hline $\mathbf{2 0}$ & Hortelã-miúdo & Medic./Comest & Folhas & $\begin{array}{l}\text { Chá/ } \\
\text { Comp.xarope/Tempero }\end{array}$ \\
\hline $\mathbf{2 1}$ & Levante & Medicinal & Folhas & Comp. xarope \\
\hline $\mathbf{2 2}$ & Mastruz & Comest.Medic. & Folha & Sumo/xarope \\
\hline $\mathbf{2 3}$ & Macaé & Medicinal & Folhas & Banho-Chá \\
\hline $\mathbf{2 4}$ & Macela & Medicinal & Folhas & Chá \\
\hline $\mathbf{2 5}$ & Malva & Medicinal & Folhas & ----------- \\
\hline $\mathbf{2 6}$ & Perpétua & Medicinal & Flor & Chá \\
\hline $\mathbf{2 7}$ & Picão & Medic.Comest. & Folha & Chá/ banho/Refogado \\
\hline $\mathbf{2 8}$ & Poeijo & Medicinal & Folhas & Xarope \\
\hline $\mathbf{2 9}$ & Ponta livre & Medicinal & Folhas & Chá \\
\hline $\mathbf{3 0}$ & Rosa Branca & Medicinal & Flor & Chá/ Comp.xarope \\
\hline $\mathbf{3 1}$ & Saião & Medicinal & Folhas & Sumo/C. xarope \\
\hline $\mathbf{3 2}$ & Sálvia & Medicinal & Folhas & Chá \\
\hline $\mathbf{3 3}$ & Santa Maria & Medicinal & Folhas & Chá/Sumo \\
\hline $\mathbf{3 4}$ & Trançagem & Medicinal & Folhas & Chá \\
\hline $\mathbf{3 5}$ & Vick & Medicinal & Folhas & Xarope/Inalação \\
\hline $\mathbf{3 6}$ & Cavalinha & Medicinal & Folha/caule & Chá \\
\hline $\mathbf{3 7}$ & Erva-tostão & Medicinal & Chá \\
\hline & & & Faiz & \\
\hline
\end{tabular}

Fonte: Elaborada pelos autores

Tabela 2- Frutíferas

\begin{tabular}{|c|c|c|c|c|}
\hline & 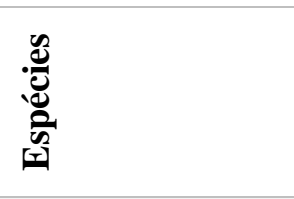 & 宽 & 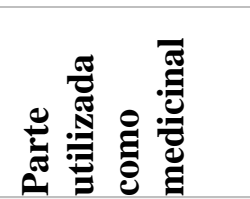 & 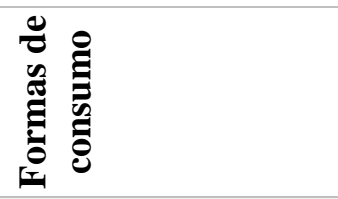 \\
\hline 01 & Abacate & Comest./Medic. & Fruto /Folhas & In Natura/Chá \\
\hline 02 & Abacaxi & Comestível/Medic. & Fruto/Casca & In Natura/Chá \\
\hline 03 & Acerola & Comestível/Medic & Fruto & In Natura/Suco \\
\hline 04 & Amora & Comest.-medic. & Fruto /Folhas & In Natura/Chá \\
\hline 05 & Banana & Comestível & Fruto & In Natura/Doce \\
\hline 06 & Banana São Tomé & Comest.-medic. & Fruto/ Umbigo & $\begin{array}{l}\text { In Natura/Rec. } \\
\text { Espec. }\end{array}$ \\
\hline 07 & Carambola & Comestível & Fruto & In Natura \\
\hline 08 & Cajá-manga & Comestível & Fruto & In Natura \\
\hline 09 & Coco & Comestível/ Medic. & Fruto/ Água & $\begin{array}{l}\text { In } \\
\text { Natura/Doce/Natural }\end{array}$ \\
\hline
\end{tabular}




\begin{tabular}{|c|c|c|c|c|}
\hline 10 & Goiaba & Comest.-medic. & Fruto/Folhas & In Natura/Chá \\
\hline 11 & Graviola & Comest./Medic. & Fruto/Folhas & In Natura/Chá \\
\hline 12 & Jabuticaba & Comestível & Fruto & In Natura \\
\hline 13 & Laranja & Comestível & Fruto/Folhas/Flores & $\begin{array}{l}\text { In } \\
\text { Natura/Comp.xarope }\end{array}$ \\
\hline 14 & Laranja Lima & Comestível & Fruto/ Folhas & In Natura/Chá \\
\hline 15 & Laranja campista & Comest.-medic. & Fruto/Folhas & $\begin{array}{l}\text { In Natura/ Rec. } \\
\text { Espec }\end{array}$ \\
\hline 16 & Lima & Comestível & Fruto/Folhas & In Natura/ Chá \\
\hline 17 & Limão & Comestível & Fruto & In Natura/ Limonada \\
\hline 18 & Mamão & Comest.-medic. & Fruto/Flores & $\begin{array}{l}\text { In Natura/ } \\
\text { Comp.xarope }\end{array}$ \\
\hline 19 & Mexirica & Comestível & Fruto/Folhas & $\begin{array}{l}\text { In Natura/ } \\
\text { Comp.xarope }\end{array}$ \\
\hline 20 & Noni & Comest,-Medic. & Fruto & In Natura/ Suco \\
\hline 21 & Pinha & Comest./Medic. & Fruto/Folha & In Natura/c/Chá \\
\hline 22 & Romã & Comest./Medic. & Fruto /Casca & $\begin{array}{l}\text { In Natura/Chá- } \\
\text { Gargarejo }\end{array}$ \\
\hline 23 & Uva & Comestível & Fruto & In Natura/suco \\
\hline
\end{tabular}

Tabela 3- Espécimes Ornamentais

\begin{tabular}{|c|c|c|c|c|}
\hline & 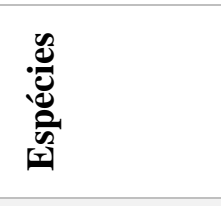 & 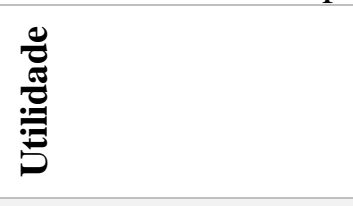 & 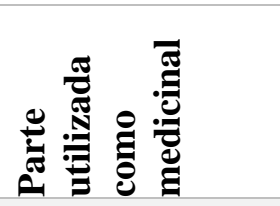 & 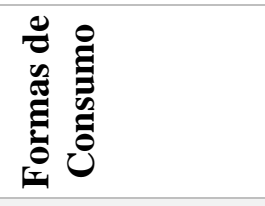 \\
\hline 01 & Alfinetinho & Ornamental & --------------- & ----------------- \\
\hline $\mathbf{0 2}$ & Antúrio & Ornamental & ------------------ & ------------------ \\
\hline $\mathbf{0 3}$ & Avenca & Ornamental & ----------------- & ----------------- \\
\hline 04 & Bambuzinho & Ornamental & ----------------- & ----------------- \\
\hline 05 & Beijo & Ornam.-Medic. & Flores & Chá \\
\hline 06 & Begônia & Ornamental & ---------------- & ---------------- \\
\hline 07 & Bromélia & Ornamental & ----------------- & ------------------ \\
\hline 08 & Cactos & Ornamental & ------------------ & ------------------ \\
\hline 09 & Camarão & Ornamental & ------------------ & ------------------ \\
\hline 10 & $\begin{array}{l}\text { Comigo } \\
\text { ninguém } \\
\text { pode }\end{array}$ & Ornamental & -------------- & ---------------- \\
\hline 11 & $\begin{array}{l}\text { Copo de } \\
\text { leite }\end{array}$ & Ornamental & ---------------- & ---------------- \\
\hline 12 & $\begin{array}{l}\text { Coroa } \\
\text { Imperial }\end{array}$ & Ornamental & ---------------- & ---------------- \\
\hline 13 & $\begin{array}{l}\text { Dama da } \\
\text { noite }\end{array}$ & Ornamental & ----------------- & ----------------- \\
\hline 14 & Dólar & Ornamental & ----------------- & ----------------- \\
\hline 15 & Flor de maio & Ornamental & ---------------- & ----------------- \\
\hline 16 & Hortência & Ornamental & ---------------- & ----------------- \\
\hline 17 & Jasmim & Ornamental & ---------------- & ---------------- \\
\hline
\end{tabular}




\begin{tabular}{|c|c|c|c|c|}
\hline 18 & Já Pudera & Ornamental/Medic. & Folhas & Receita especial \\
\hline 19 & Joaninha & Ornamental & ----------------- & Tempero \\
\hline 20 & Lírio & Ornamental & ------------------- & ------------------- \\
\hline 21 & Manacá & Ornamental & ---------------- & ----------------- \\
\hline 22 & $\begin{array}{l}\text { Mini copo } \\
\text { de leite }\end{array}$ & Ornamental & ----------------- & ------------------ \\
\hline 23 & Murta & Ornamental & ------------------ & ------------------ \\
\hline 24 & Orquídea & Ornamental & ------------------- & ------------------- \\
\hline 25 & $\begin{array}{l}\text { Pimenta } \\
\text { Biquinho }\end{array}$ & Ornamental- Comest. & Fruto & Conserva \\
\hline 26 & $\begin{array}{l}\text { Pimenta } \\
\text { dedo de } \\
\text { moça }\end{array}$ & Ornamental- Comest. & Fruto & Tempero \\
\hline 27 & $\begin{array}{l}\text { Renda } \\
\text { Portuguesa }\end{array}$ & Ornamental & ---------------- & ---------------- \\
\hline 28 & Rosas & Ornamental & ------------------ & ------------------ \\
\hline 29 & $\begin{array}{l}\text { Rosa } \\
\text { vermelha }\end{array}$ & Ornam./Medic & Pétalas & Chá \\
\hline 30 & Rosa branca & Ornam./Medic & Flor & Chá \\
\hline 31 & $\begin{array}{l}\text { Renda } \\
\text { Portuguesa }\end{array}$ & Ornamental & -------- & ---------------- \\
\hline 32 & Samambaia & Ornamental & ----------------- & ----------------- \\
\hline 33 & $\begin{array}{l}\text { Sangue de } \\
\text { Cristo }\end{array}$ & Ornamental-Medicinal & Folhas & Chá \\
\hline
\end{tabular}

Fonte: Elaborada pelos autores

Tabela 4- Espécimes alimentícias/comestíveis

\begin{tabular}{|c|c|c|c|c|}
\hline & 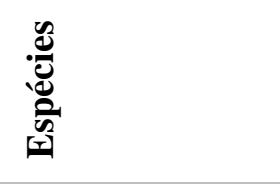 & 苞 & 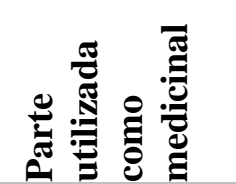 & 馬 \\
\hline 01 & Abóbora & Comestível & Fruto-Broto & Refogado \\
\hline 02 & Alfavaca & Comestível & Folhas & $\begin{array}{l}\text { Tempero } \\
\text { Comp xarope }\end{array}$ \\
\hline 03 & Araruta & Comest./Medic. & Raiz & Polvilho \\
\hline 04 & Batata doce & Comestível & Raiz/Folha & $\begin{array}{l}\text { Doce- } \\
\text { Refogada }\end{array}$ \\
\hline 05 & Cebolinha & Comestível & Folhas & Tempero \\
\hline \multirow[t]{2}{*}{06} & Couve & Comestível & Folhas & Refogado \\
\hline & Couve roxa & $\begin{array}{l}\text { Comestível/ } \\
\text { Medicam. }\end{array}$ & Folhas e talos & $\begin{array}{l}\text { Refogado } \\
\text { Suco }\end{array}$ \\
\hline 07 & Hortelã-pimenta & Comestível & Folhas & Tempero \\
\hline 08 & Jurubeba & Comestível & Fruta & $\begin{array}{l}\text { Refogado } \\
\text { Conserva }\end{array}$ \\
\hline 09 & Mandioca & Comest./Medic. & Raiz & $\begin{array}{l}\text { Bolo, Farinha, } \\
\text { refogada; } \\
\text { Emprasto }\end{array}$ \\
\hline
\end{tabular}




\begin{tabular}{|c|c|c|c|c|}
\hline 10 & Manjericão & Comestível & Folhas & Tempero \\
\hline 11 & Maxixe & Comestível & Fruto & $\begin{array}{l}\text { Refogado e } \\
\text { salada }\end{array}$ \\
\hline 12 & Quiabo & Comestível & $\begin{array}{l}\text { Fruto- Folhas } \\
\text { novas }\end{array}$ & Refogados \\
\hline 13 & Salsa & Comest. Medicam. & Folhas/Raiz & $\begin{array}{l}\text { Tempero } \\
\text { Chá }\end{array}$ \\
\hline 14 & Serralha & Comest./Medic. & Folhas & $\begin{array}{l}\text { Refogado } \\
\text { Sumo }\end{array}$ \\
\hline
\end{tabular}

Fonte: Elaborada pelos autores

Observou-se uma grande variedade de espécies tanto medicinais, quanto comestíveis e ornamentais no quintal de Dona Luísa, também chamou atenção a utilização dessas plantas pela família Souza, vizinhos entre outras pessoas.

As partes dos vegetais utilizadas para consumo são o fruto, as folhas, raízes, sementes e o caule, (Tabelas 2 e 4). Os frutos são as partes mais consumidas visto que além de muitos serem consumidos in natura, são utilizados na preparação de geleias, doces, conservas, chás e sucos.

Ao observar a separação de plantas em categorias chama atenção que uma planta pode ter uso duplo, isso é ter ao mesmo tempo mais de uma utilidade.

As espécies mais utilizadas pela depoente são as medicinais, uma prática já antiga, porém ainda frequente, pois quando residia na roça, a distância, falta de condução e o difícil acesso dificultava a frequência a médicos. E mesmo atualmente residindo na cidade, a prática e eficiência das receitas utilizando-se de ervas medicinais do próprio quintal sobressai sobre a medicina acadêmica. Bem como, estar residindo em zona urbana, próximo à mercados, não alterou a antiga prática de retirar do próprio quintal uma série de alimentos tais como verduras, temperos, farinhas, polvilho, frutas diversas e doces.

Foi possível observar o quanto é significativo e amplo o conhecimento da Sra Souza sobre o uso das espécies, tipo de conhecimento que também foi observado por Santos et al (2013) que relatou que a sabedoria sobre o uso de uma gama de espécies é de fato mais expressivo entre os idosos.

Próximo à casa da família Souza outras famílias também possuem plantas, mas diferente das encontradas no quintal estudado, pois são cultivadas em vasos e a maioria das plantas dos quintais vizinhos são ornamentais. 


\section{6- CONSIDERAÇÕES FINAIS}

Da mudança da área rural onde a família de Dona Luiza Souza se constituiu como identidade de negros rurais, houve a necessidade de guardar hábitos e heranças culturais que se consolidaram na casa em Natividade e no quintal da casa. O quintal é um quintal urbano, com muitos elementos transplantados da zona rural. Sendo de grande importância social, para família, vizinhos e a comunidade mais ampla da cidade a socialização dos resultados e a procura pelos produtos.

Os conhecimentos e o modo de vida na arquitetura do quintal obedecem a ritos e conhecimentos transmitidos pela mãe da dona Luiza Souza e pertence à memória da família Souza. Os conhecimentos da etnobotânica de base africana é evidência comprovada pelo número de espécies encontradas no quintal e pelas detalhadas explicação dos usos e formas de cultivo e maneiras de colheita. As famílias mantem a tradição de onde moravam anteriormente, a casa com varanda características do ambiente rural no qual constituíram família. É como se eles estivessem na roça, tanto que preservam antigos hábitos como uso de peneiras, pilões, engenhoca, jirau, tachos, balaios além do quintal que preserva a diversidade de espécies alimentares, medicinais e ornamentais apresentadas.

No quintal se consolidam memória, história, acervo de conhecimento e práticas culturais e se configuram-se num patrimônio do sentido material e imaterial da população negra. Portanto é uma das formas urbana das populações negras (CUNHA JUNIOR, 2019). Uma forma que era mais comum no passado e hoje esta em desaparecimento nos bairros negros da cidade. Utilizando a terminologia empregada por Renata Aquino Silva, na sua tese de doutoramento e na descrição de um território de maioria da população negra (SILVA, 2014), esse quintal é uma Afro-inscrição urbana dessa população. Também conforme Santos e Cunha Júnior (2019), esse quintal guarda muitos elementos em comum com quintais estudados em comunidades de quilombos no Ceará.

\section{REFERÊNCIAS BIBLIOGRÁFICAS}


ALMEIDA, MARA ZÉLIA DE. Plantas medicinais. 3. ed. - Salvador: EDUFBA, (p. 01 -224), 2011.

BARRETO, Rosivalda dos Santos. Patrimônio Cultural, Infância e Identidade no Bairro de Bom Juá: Salvador - Bahia. Fortaleza: Dissertação (Mestrado em Educação) - Universidade Federal do Ceará, 2012.

BASTIDE, Roger, Candomblé na Bahia. Rito nagô, São Paulo, Companhia das Letras, 2001

BRITO, M. A.; COELHO, M. de F. Os quintais agroflorestais em regiões tropicais - unidades auto-sustentáveis. Agricultura Tropical, v. 4, n. 1, p. 7-35, 2000

CARVALHO, Rosane Aparecida Bartholazzi. Imigrantes italianos em uma nova fronteira: Noroeste Fluminense (1896 - 1930). Dissertação (Mestrado) Universidade Severino Sombra Vassouras. 2001.

CUNHA JUNIOR, Henrique. Bairros Negros: A Forma Urbana das Populações Negras no Brasil. Revista ABPN, v. 11, p. 65-86, 2019.

FROTA JÚNIOR, Itamar; WEHMANN, Hulda. O ensino de Paisagismo como Experiência Interdisciplinar. A integração da Arquitetura e Agronomia no ensino de Paisagismo no curso de Arquitetura e Urbanismo da Estácio - FIC. Anais do 12 ENEPA. Agosto de 2014.

GOMES, Ângela Maria da Silva. Rotas e diálogos de saberes da etnobotânica transatlântica negro-africana: terreiros, quilombos, quintais da Grande BH-Tese (doutorado) 2010. 220 f. Universidade Federal de Minas Gerais, Instituto de Geociências, Belo Horizonte, MG.

GOMES, Gabriela Schmitz. Quintais agroflorestais no município de Irati-Paraná, Brasil: agrobiodiversidade e sustentabilidade socioeconômica e ambiental. 2010. 161 f. Tese (Doutorado em Ciências Florestais) - Setor de Ciências Agrárias, Universidade Federal do Paraná, Curitiba, 2010.

MAVOUNGOU-YADE, Juliana de Souza. Vozes e Territorialidades no Pós-Abolição: histórias de famílias e resistência identitaria. 2015. Tese (Doutorado em Educação) Universidade Federal do Ceará, 2015.

PALHETA, Ivanete Cardoso. Quintais urbanos e plantas medicinais: um estudo etnobotânico no bairro São Sebastião, Abaetetuba-PA. Dissertação (Mestrado em Ciências Ambientais) Universidade do Estado do Pará, Centro de Ciências Naturais e Tecnologia, Belém, 2015.

PEDROSA, Rosangela Aparecida. A importância dos quintais produtivos na economia familiar. AGROECOL, 2016.

RANIERI, Guilherme Reis; ZANIRATO, Silvia Helena. Conhecimento etnobotânico como patrimônio: os quintais urbanos nas pequenas cidades do Vale Histórico Paulista. Desenvolv. Meio Ambiente, v. 49, p. 183-199, dezembro 2018.

SANTANA, Gisane Souza; SIMÕES, Maria de Lourdes Netto. Identidade, memória $e$ patrimônio: a festa de Sant'Ana do Rio do Engenho, Ilhéus (BA). Textos escolhidos de cultura e arte populares, Rio de Janeiro, v.12, n.1, p. 87-102, mai. 2015. 
SANTILLI, J. O reconhecimento de comidas, saberes e práticas alimentares como patrimônio cultural imaterial. DEMETRA: Alimentação, Nutrição \& Saúde, 10(3), 585-606, 2015. doi: 10.12957/demetra.2015.16054

SANTOS, Amaury da S.; OLIVEIRA, Lanna C. L. de; CURADO, Fernando F.; AMORIM, Lucas O. Caracterização e desenvolvimento de quintais produtivos agroecológicos na comunidade Mem de Sá, Itaporanga d'Ajuda-Sergipe. Revista Brasileira de Agroecologia de Agroecologia. 8(2): 100-111. 2013.

SANTOS, Marlene Pereira dos; CUNHA JÚNIOR, Henrique. A farmácia em casa: ancestralidade e conhecimento em botânica em Horizonte. In Afropatrimônio Cultural. Série Conhecimento Africano e Afro-brasileiro: Volume 1. Editora Via Dourada. Fortaleza-CE, 2019.

SANTOS, M. P. dos. Incursão na história e memória da Comunidade de Quilombo de Alto Alegre município de Horizonte - CE. 2012. Dissertação (Mestrado em Educação) Universidade Federal do Ceará, Fortaleza, 2012

SILVA, Renata Aquino da. Afroinscrições Negras em Petrópolis - Historia Urbana, Memória e Territorialidade. 2018. Tese (Doutorado em Educação) - Universidade Federal do Ceará, 2018.

SILVA, Renata A. da; CUNHA JUNIOR, Henrique. Cidades Negras - Petrópolis Imperial. Revista Ambivalências, v. 2, p. 81, 2014.

SOUZA, Márcia Aparecida de; CUNHA JUNIOR, Henrique. Festança de família negra tradicional do interior do Rio de Janeiro: memória, história e patrimônio cultural da população negra. In: Afro patrimônio cultural. SANTOS, Marlene Pereira dos e CUNHA JÚNIOR, Henrique. Fortaleza, CE: Editora Via Dourada, 2019.

Recebido em: 22/09/2020

Aceito em: 30/10/2020 